\title{
Cancer-associated fibroblasts promote cisplatin resistance in bladder cancer cells by increasing IGF-1/ERß/BCl-2 signalling
}

Xingbo Long ${ }^{1,2}$, Wei Xiong ${ }^{1}$, Xiting Zeng ${ }^{3}$, Lin Qi ${ }^{1}$, Yi Cai ${ }^{1}$, Miao Mo ${ }^{1}$, Huichuan Jiang ${ }^{1}$, Bisong Zhu ${ }^{1}$, Zhi Chen ${ }^{1}$ and Yuan Li (10)

\begin{abstract}
While cancer-associated fibroblasts (CAFs) in the tumour microenvironment may play important roles in bladder cancer (BCa) progression, their impacts on BCa chemoresistance remain unclear. Using human BCa samples, we found that tumour tissues possessed more CAFs than did adjacent normal tissues. Both the presence of CAFs in the BCa stroma and the expression of ER $\beta$ in BCa contribute to chemoresistance, and CAFs and BCa cells interact to affect ER $\beta$ expression. In vitro co-culture assays demonstrated that compared with normal bladder cells, BCa cells had a higher capacity to induce the transformation of normal fibroblasts into CAFs. When BCa cells were co-cultured with CAFs, their viability, clone formation ability and chemoresistance were increased, whereas their apoptotic rates were downregulated. Dissection of the mechanism revealed that the recruited CAFs increased IGF-1/ERß signalling in BCa cells, which then led to the promotion of the expression of the anti-apoptotic gene Bcl-2. Blocking IGF-1/ERB/BCl2 signalling by either an shRNA targeting ERB or an anti-IGF-1 neutralizing antibody partially reversed the capacity of CAFs to increase BCa chemoresistance. The in vivo data also confirmed that CAFs could increase BCa cell resistance to cisplatin by increasing ERB/BCl-2 signalling. The above results showed the important roles of CAFs within the bladder tumour microenvironment, which could enhance BCa chemoresistance.
\end{abstract}

\section{Introduction}

Bladder cancer $(\mathrm{BCa})$ is one of the most common types of urinary tract malignancy ${ }^{1}$. At initial diagnosis, approximately $30 \%$ of patients are diagnosed with muscleinvasive $\mathrm{BCa}(\mathrm{MIBC})^{2}$. Chemotherapy is a major treatment choice for MIBC patients, especially for high-risk patients, and this approach can effectively inhibit tumour growth and postpone tumour recurrence ${ }^{3,4}$. Cisplatin serves as the first-line chemotherapy for advanced BCa. Unfortunately, most patients benefit little from chemotherapy due to chemoresistance ${ }^{3}$. Growing evidence

\footnotetext{
Correspondence: Yuan Li (yuanlixy@csu.edu.cn)

'Department of Urology, Xiangya Hospital, Central South University, Changsha 410008 Hunan, China

2Department of Urology, Beijing Hospital, National Centre of Gerontology,

Graduate School of Peking Union Medical College, 100730 Beijing, China

Full list of author information is available at the end of the article.

Edited by A. Peschiaroli
}

indicates that the tumour microenvironment may play crucial roles in inducing the acquisition of chemoresistance in various tumours, and this microenvironment has become a major focus in modelling therapeutic respon$\mathrm{ses}^{5-7}$. Cancer-associated fibroblasts (CAFs), the activated phenotype of fibroblasts within tumours, are the most abundant stromal cells in various tumour microenvironments ${ }^{8,9}$. Recent research has shown that CAFs not only play an important role in tumour growth, angiogenesis and dissemination but also regulate chemoresistance in multiple types of solid tumour cells, including breast, ovarian and lung cancer ${ }^{10-12}$. However, to the best of our knowledge, few studies have discussed the role of CAFs in the acquisition of chemoresistance by $\mathrm{BCa}$.

Epidemiological studies have demonstrated that women have a lower incidence of $\mathrm{BCa}$, yet when they do have the disease, women have higher rates of MIBC and recurrence

\section{(c) The Author(s) 2019}

(c) (i) Open Access This article is licensed under a Creative Commons Attribution 4.0 International License, which permits use, sharing, adaptation, distribution and reproduction cc) in any medium or format, as long as you give appropriate credit to the original author(s) and the source, provide a link to the Creative Commons license, and indicate if changes were made. The images or other third party material in this article are included in the article's Creative Commons license, unless indicated otherwise in a credit line to the material. If material is not included in the article's Creative Commons license and your intended use is not permitted by statutory regulation or exceeds the permitted use, you will need to obtain permission directly from the copyright holder. To view a copy of this license, visit http://creativecommons.org/licenses/by/4.0/. 
and a poorer prognosis than do men ${ }^{13,14}$, indicating that oestrogen and oestrogen receptors (ERs) may play critical roles in the initiation and proliferation of $\mathrm{BCa}$ through specific receptor-induced signalling pathways. ER alpha $(E R \alpha)$ and ER beta $(E R \beta)$ are two major types of ERs that mediate the effects of oestrogen in various tissues ${ }^{15}$. Compared with ER $\alpha, E R \beta$ has been proven to be more predominant in human bladder and $\mathrm{BCa}$ tissues $^{16,17}$. Moreover, an increasing number of clinical studies has demonstrated that ER $\beta$ is a biomarker correlated with poor clinical outcomes in $\mathrm{BCa}$ patients ${ }^{17-20}$. In addition, several in vivo and in vitro studies have suggested that ER $\beta$ signalling pathways are involved in progression, invasion and anti-apoptotic events in $\mathrm{BCa}$ cells $^{21,22}$. However, the relationship between the ER $\beta$ signalling pathway and $\mathrm{BCa}$ chemoresistance and the potential mechanisms involved remain unclear. Herein, our study aimed to investigate whether CAFs regulate the sensitivity of $\mathrm{BCa}$ cells to chemotherapy and whether $\mathrm{ER} \beta$ is involved in the effect of CAFs on BCa cells.

\section{Results \\ CAFs and ER $\beta$ were correlated with cisplatin-based chemosensitivity and prognosis in MIBC patients}

The clinicopathological characteristics of 28 MIBC patients who received cisplatin-based neo-adjuvant chemotherapy (NAC) are described in Supplementary Table S1. At the time of radical cystectomy (RC) after NAC, 7 (25.0\%) patients were identified as having a pathologic complete response (pCR, ypT0N0; ypT depicts the pathologic stage after neo-adjuvant treatment), 12 (42.9\%) patients were identified as having a pathologic partial response (pPR, ypT0N0 < ypT $\leq$ ypT1N0, including ypT1/ Tis/Ta), and $9(32.1 \%)$ patients were identified as having a pathologic non-response (pNR, ypT $\geq$ ypT2).

Expression of $\alpha$-smooth muscle actin ( $\alpha$-SMA) and ER $\beta$ in adjacent normal bladder tissues, pretreatment biopsy samples and excised RC specimens were quantified using the methods described in the Supplementary Materials and Methods. The expression of $\alpha$-SMA, a CAF-specific marker, was found mostly in myofibroblasts, with lower expression in vascular pericytes ${ }^{23,24}$. BCa cells were negative for $\alpha$-SMA staining (Fig. 1a). ER $\beta$ expression was found mostly in tumour cells (Fig. 1b).

Both the $\alpha$-SMA and ER $\beta$ scores were much higher in $\mathrm{BCa}$ tissues than in adjacent normal bladder tissues, whereas there was no difference between adjacent normal bladder tissues with and without NAC (Fig. 1c). In the pCR group, the $\alpha$-SMA and ER $\beta$ scores in the pretreatment biopsy tissues were much lower than those in the pPR and pNR groups. In the pPR and pNR groups, the $\alpha$ SMA and ER $\beta$ scores were significantly higher in the RC tissues than in the pretreatment biopsy tissues (Fig. 1c). Moreover, we found that in the pretreatment biopsy tissues, $\alpha$-SMA expression in the cancer-associated stroma was correlated with ER $\beta$ expression in BCa tissues (Fig. 1d, Pearson correlation coefficient $=0.52, P<$ 0.01 ), and this correlation was much stronger in the RC tissues after NAC treatment (Fig. 1d, Pearson correlation coefficient $=0.70, P<0.001)$. Univariate analysis showed that a higher cT stage (>cT2) and higher $\alpha$-SMA and ER $\beta$ scores were predictors of a pathologic non-response (Supplementary Table S2). Predictors likely to be associated with a pathologic non-response $(P<0.1$ in the univariate analysis) were selected in the multivariable analysis; higher cT stage ( $>\mathrm{cT} 2)$ and a higher ER $\beta$ score were independent predictors of a pathologic nonresponse.

To determine if the expression of $\alpha$-SMA and ER $\beta$ in the pretreatment biopsy tissues was associated with the prognosis of MIBC patients receiving cisplatin-based NAC, we analysed overall survival (OS) and progression-free survival (PFS) with the log-rank test and Kaplan-Meier survival curves (Fig. 1e, f). The results showed that both OS and PFS were significantly lower in patients with high levels of $\alpha$-SMA and ER $\beta$ expression than in patients with low levels of $\alpha$-SMA and ER $\beta$ expression.

\section{Cisplatin accelerated the transition from NFs to CAFs}

To compare the capacities of $\mathrm{BCa}$ and normal bladder cells to activate normal fibroblasts (NFs) towards CAFs, we applied an in vitro transwell co-culture system. We placed NFs in the upper chambers and then placed BCa cells or normal bladder cells (SV40-transformed human uroepithelial cells, SVHUCs) in the lower chambers (Fig. 2a). When testing the capacity of $\mathrm{BCa}$ cells to recruit fibroblasts, we employed a fibroblast recruitment assay. After $8 \mathrm{~h}$ of incubation, the number of NFs that migrated through the membranes into the lower chambers was counted and compared with the number of NFs that migrated towards SVHUCs, and we observed that $\mathrm{BCa}$ cells had a greater capacity to recruit fibroblasts than did SVHUCs (Fig. 2b). In addition, we employed a transwell noncontact co-culture system to test the capacity of $\mathrm{BCa}$ cells to induce the transition of NFs towards CAFs. After $8 \mathrm{~h}$ of incubation, an $\alpha$-SMA immunofluorescence staining assay was implemented on all of the fibroblasts in the upper chambers, and the percentage of $\alpha-\operatorname{SMA}(+)$ fibroblasts was determined (Fig. 2c, the first column of Fig. 2g, no cisplatin treatment). In addition, the protein and mRNA levels of ACTA2 ( $\alpha$-SMA) and FAP, two CAFspecific markers, in the fibroblasts in the upper chambers were analysed by western blotting and quantitative realtime PCR (qRT-PCR), respectively (Fig. 2d). The results show that $\mathrm{BCa}$ cells had a much higher capacity than the non-malignant SVHUCs to induce NF transformation to CAFs (fibroblasts with high levels of $\alpha$-SMA and FAP 


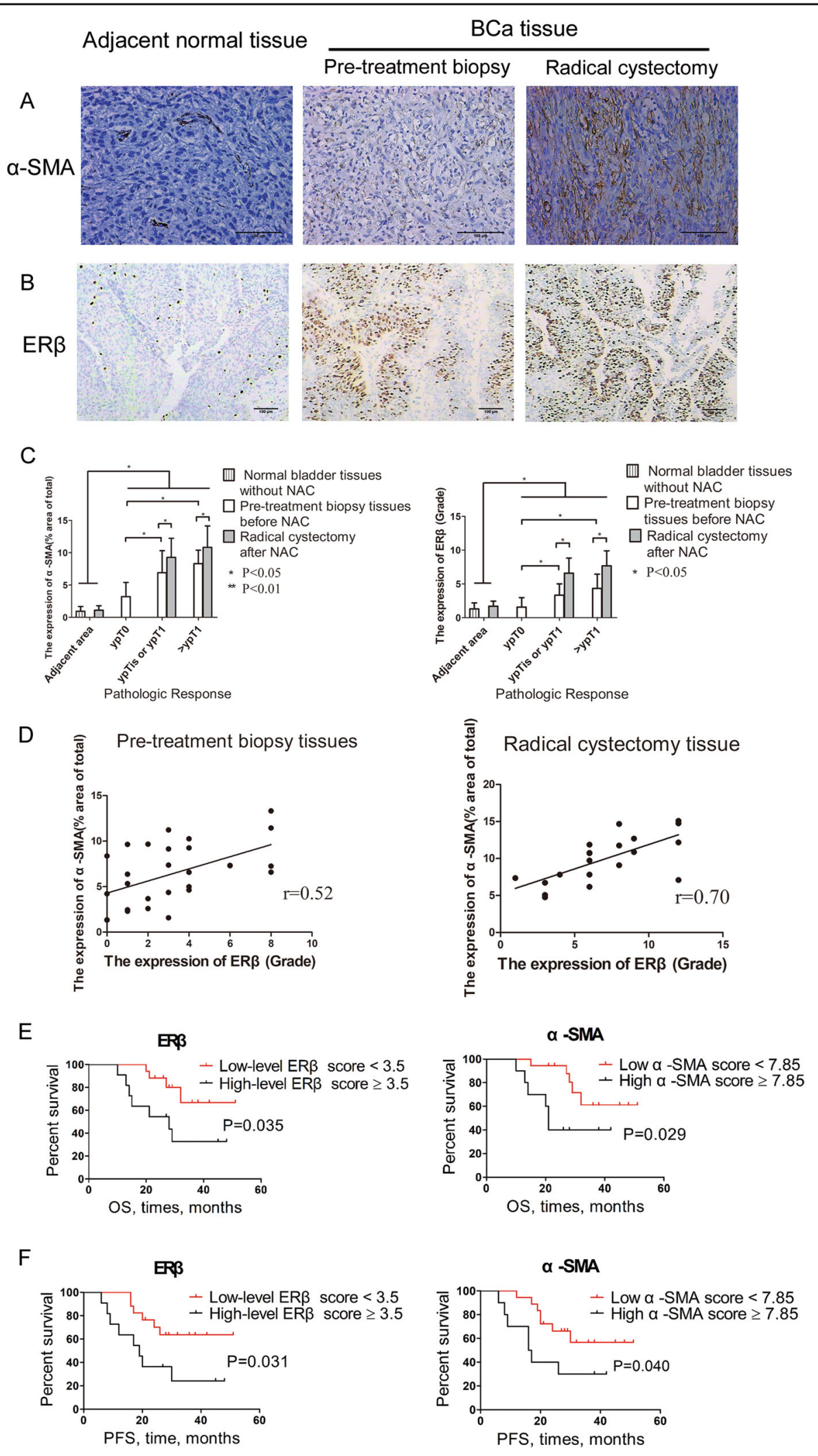

Fig. 1 (See legend on next page.) 
(see figure on previous page)

Fig. 1 The clinicopathological data of 28 MIBC patients who received cisplatin-based NAC. $\mathbf{a}$, $\mathbf{b}$ The expression of a-SMA (a) and ERB (b) in adjacent normal bladder, pretreatment biopsy and resected RC samples (a-SMA $\times 200$, ER $\beta \times 100$ ). c a-SMA (left) and ER $\beta$ (right) scores in the adjacent normal bladder with or without NAC treatment and in the pretreatment biopsy and resected RC specimens with different pathological outcomes. $\mathbf{d}$ The correlation of a-SMA expression in the cancer-associated stroma and BCa ERß expression in the pretreatment biopsy tissues (left) and RC (right) tissues. e, f Kaplan-Meier survival curves of OS (e) and PFS (f) in the 28 patients. The results indicated that a-SMA and ER $\beta$ expression was related to OS and PFS. Data are presented as the mean \pm SD. ${ }^{*} P<0.05$

expression) (Fig. 2c, d). Then, we added different concentrations of cisplatin to the conditioned medium (CM) of $\mathrm{BCa}$ cells. After $8 \mathrm{~h}$ of incubation, we found that at certain concentrations of cisplatin $(10 \mathrm{mg} / \mathrm{L}$ for the T24 group and $4 \mathrm{mg} / \mathrm{L}$ for the 5637 group), the percentage of NFs that transitioned to CAFs was increased. As the concentration of cisplatin further increased, the protein and mRNA levels of ACTA2 and FAP in the fibroblasts and the percentage of $\alpha-\mathrm{SMA}(+)$ fibroblasts decreased rapidly (Fig. 2e-g). The above data indicate that compared with non-malignant SVHUCs, BCa cells have an increased capacity to recruit fibroblasts and induce the transformation of NFs to CAFs, and appropriate concentrations of cisplatin can accelerate these processes.

\section{CAFs enhanced chemoresistance in BCa cells}

Compared with the cells cultured without CAFs, cells (both T24 and 5637 cells) co-cultured with CAFs exhibited dramatically increased survival rates (Fig. 3a). The IC50 results showed that co-culture with CAFs decreased the sensitivity of both T24 and 5637 cells to cisplatin (Fig. $3 b)$. Furthermore, a colony formation assay showed that the proliferation of both cell lines was enhanced after coculture with CAFs $(P<0.05)$ (Fig. 3c). In addition, flow cytometry revealed that co-culture of either T24 or 5637 cells with CAFs decreased apoptosis of these uroepithelial cell lines (Fig. 3d, e). Finally, we observed that after exposure to cisplatin (T24, $25 \mathrm{mg} / \mathrm{L} ; 5637,6 \mathrm{mg} / \mathrm{L}$ ), the levels of cleaved caspase-3, a key mediator of apoptosis, in both T24 and 5637 cells was significantly increased, whereas this value was decreased in the presence of CAFs (Fig. 3f). The above data indicate that co-culture with CAFs could promote proliferation and protect $\mathrm{BCa}$ cells from cisplatin-induced apoptosis.

\section{Silencing ER $\beta$ alleviates chemoresistance induced by CAFs in $\mathrm{BCa}$ cells}

The mRNA and protein levels of ER $\beta$ were increased in BCa cells after co-culture with CAFs (Fig. 4a, b). ER $\beta$ was knocked down in $\mathrm{BCa}$ cells by ER $\beta$-short hairpin RNA (shRNA), and western blotting (Fig. 4c, right) and qRTPCR (Fig. 4c, left) analysis verified the ER $\beta$ knockdown efficacy $48 \mathrm{~h}$ after transfection in both $\mathrm{BCa}$ cell types. Suppression of ER $\beta$ could reverse CAF-promoted cisplatin resistance in both T24 and 5637 cells (Fig. 4d, e). To further elucidate the mechanisms by which ER $\beta$ signalling might contribute to CAF-promoted $\mathrm{BCa}$ resistance to cisplatin-induced apoptosis, we screened for the expression of a group of apoptosis-related genes. We found that the expression of the anti-apoptotic gene $\mathrm{Bcl}-2$ was consistently higher in BCa cells after co-culture and could be partially reversed by ER $\beta$ knockdown (Fig. 4f). Next, western blotting demonstrated that the protein level of Bcl-2 was selectively increased in the two BCa cell lines after co-culture with CAFs and was decreased after knocking down ER $\beta$ (Fig. 4g). The results shown in Fig. 4 proved that CAFs could decrease cisplatin-induced $\mathrm{BCa}$ apoptosis via modulation of $\mathrm{ER} \beta / \mathrm{Bcl}-2$ signalling in $\mathrm{BCa}$ cells.

\section{CAFs regulated ER $\beta$ expression via IGF-1/AKT signalling}

Previous studies have shown that CAFs may affect chemotherapy resistance through cytokine and chemokine production ${ }^{25}$. A group of cytokines reported to be associated with chemotherapy resistance were screened with their corresponding enzyme-linked immunosorbent assay (ELISA) kits (data not shown). A higher level of insulin-like growth factor 1 (IGF-1), a well-known autocrine and paracrine inducer of CAF activation ${ }^{9}$, was detected in the co-cultured CM than in the CM from cells grown without co-culture (Fig. 5a, left). In the co-culture $\mathrm{CM}$, the level of IGF-1 was even higher in the presence of an appropriate concentration of cisplatin (Fig. 5a, right). qRT-PCR also confirmed that IGF-1 mRNA transcripts were most abundant in CAFs after co-culture (Fig. 5b). Furthermore, in human clinical samples, we found that IGF-1 was abundant in the tumour stroma CAFs in RC tissues from the pNR group (Fig. 5c). Then, $10 \mu \mathrm{g} / \mathrm{mL}$ anti-IGF-1 neutralizing antibody was applied to suppress the effect of IGF-1, and the results indicated that blocking IGF-1 could partially reverse CAF-mediated upregulation of $\mathrm{ER} \beta$ and $\mathrm{Bcl}-2$ in BCa cells (Fig. 5d) and CAF-mediated promotion of cisplatin resistance in $\mathrm{BCa}$ (Fig. 5e). Importantly, blocking IGF-1 in the co-culture system also reversed the capacity of $\mathrm{BCa}$ cells to induce the transformation of NFs to CAFs (Fig. $5 \mathrm{f}$ ) and recruit fibroblasts (Fig. 5 g). Next, we added $100 \mathrm{ng} / \mathrm{mL}$ IGF- 1 to the CM of $\mathrm{BCa}$ cells to observe the effects of excess IGF-1. The results suggested increased expression of ER $\beta$ and $\mathrm{Bcl}-2$ in the $\mathrm{BCa}$ cells (Fig. 5h). Importantly, adding IGF-1 also increased cisplatin resistance of BCa cells (Fig. 5i). These results indicated that the IGF-1/ER $\beta / \mathrm{Bcl}-2$ signalling axis 


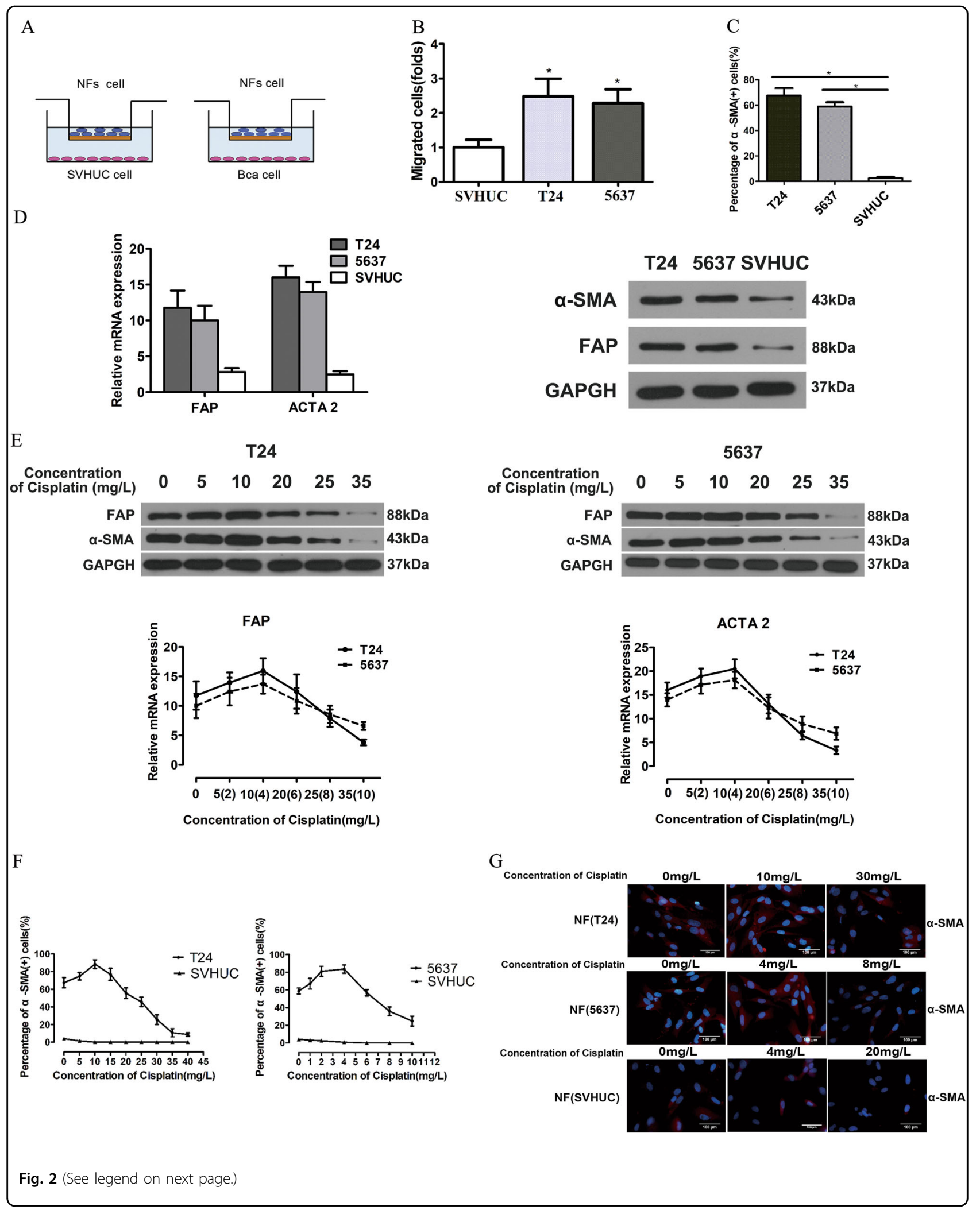


(see figure on previous page)

Fig. 2 BCa cells can better promote the transformation of NFs into CAFs than non-malignant bladder cells, and appropriate

concentrations of cisplatin can accelerate this process. a Cartoon showing the transwell co-culture system: CM from BCa cells or SVHUCS was plated into the lower chambers of the transwells, and $1 \times 10^{5} \mathrm{NFs}$ cells were plated onto the upper chambers. When implementing fibroblast recruitment assays, a polycarbonate membrane with a $5-\mu \mathrm{m}$ pore size was inserted between the two chambers. For the noncontact co-culture system, a polycarbonate membrane with a $0.4-\mu \mathrm{m}$ pore size was used. b After $8 \mathrm{~h}$ of incubation, the fibroblasts that migrated into the lower chambers were collected and counted. c The a-SMA immunofluorescence staining assay was implemented on all fibroblasts in the noncontact coculture system after $8 \mathrm{~h}$ of incubation, and the percentage of a-SMA(+) fibroblasts was counted. $\mathbf{d}$ Western blot and quantitative real-time PCR (qRTPCR) results showed the expression of the CAF-specific markers ACTA2 (a-SMA) and FAP in fibroblasts in the noncontact co-culture system after $8 \mathrm{~h}$ of incubation. e Different concentrations of cisplatin were added to the noncontact co-culture system. After $8 \mathrm{~h}$ of incubation, the protein and mRNA levels of ACTA2 and FAP in fibroblasts were analysed. $\mathbf{f}, \mathbf{g}$ Different concentrations of cisplatin were added to the noncontact co-culture system. After $8 \mathrm{~h}$ of incubation, the percentage of a-SMA(+) fibroblasts was counted in the upper chambers using immunofluorescence. The first column of Fig. $2 \mathrm{~g}$ (no cisplatin added) is also the experimental condition of Fig. 2c. In the qRT-PCR analysis, we used the $\beta$-actin gene as the normalization control. Data are presented as the mean \pm SD. ${ }^{*} P<0.05$

might play vital roles in mediating CAF-induced cisplatin resistance in $\mathrm{BCa}$ cells.

To further study the signals downstream of IGF-1 that are involved in the upregulation of ER $\beta$ expression, we investigated the phosphorylation of several molecules, including IGF-1 receptor (IGF-1R) and its downstream signalling protein AKT. The expression of IGF-1R and the phosphorylation of IGF-1R and AKT were increased dramatically in the co-culture system and decreased by blocking IGF-1. However, co-culture did not influence the levels of total AKT protein (Fig. 6a).

To determine whether activation of IGF-1R and AKT by IGF-1 was required for IGF-1-mediated stimulation of $\mathrm{ER} \beta$ expression in $\mathrm{BCa}$, we used the specific IGF-1R inhibitor AG1024 (AG; Millipore, Boston, MA, USA) and the AKT inhibitor LY294002 (LY; CST, Boston, MA, USA) for further study. We found that AG could partially reverse CAF-mediated activation of the AKT signalling pathways (Fig. 6b). In addition, treatment with both AG and LY could markedly reduce ER $\beta$ and Bcl-2 protein (Fig. 6b, c) and mRNA (Fig. 6d) expression after $48 \mathrm{~h}$ of co-culture. In addition, flow cytometry showed that both AG and LY could reverse CAF-mediated cisplatin resistance in T24 and 5637 cells (Fig. 3e). Together, these findings indicate that IGF- 1 increased ER $\beta$ expression via the IGF-1/IGF-1R/AKT signalling axis.

\section{IGF-1/AKT signalling activated c-Jun phosphorylation and promoted ESR2 gene transcription}

To further investigate how AKT signalling increases ER $\beta$ expression, we mapped the human ESR2 promoter region, which was found to contain multiple recognition motifs for sequence-specific transcription factors, including $\mathrm{c}-\mathrm{Jun}^{26,27}$. In addition, previous findings showed that in rat tumour Leydig cells, IGF-1 had the ability to activate c-Jun ${ }^{28}$. Figure $6 \mathrm{f}$ shows that phosphorylation of c-Jun proteins was increased dramatically in the coculture system and decreased by blocking IGF-1, IGF-1R and AKT signalling. Then, a chromatin immunoprecipitation (ChIP) assay was applied to verify the extent of c-
Jun binding to the ESR2 promoter in BCa cells. Cells were treated with or without IGF-1 for $8 \mathrm{~h}$, and ChIP with antic-Jun antibodies followed by ESR2 promoter PCR was then performed. The results show a significant increase in c-Jun binding after treated with IGF-1 (Fig. 6g, h). All of these results indicate that CAFs increased ER $\beta$ expression via IGF-1/AKT/c-Jun signalling.

\section{CAFs reduced $\mathrm{BCa}$ sensitivity to cisplatin in an animal model}

To confirm these results in an in vivo mouse model, verification and interference studies were performed. The grouping and intervention schemes were as described in the Materials and methods shown in Fig. 7a. In the verification study, we subcutaneously xenografted nude mice with T24 cells co-implanted with or without CAFs. In the interference study, we subcutaneously xenografted nude mice with T24 cells co-implanted with CAFs and treated mice with the IGF-1R inhibitor AG. Figure 7b shows the change in tumour volume during the in vivo verification and interference study. After the mice were sacrificed, the tumours were harvested. The results showed that among the untreated groups, mice in group 2 had a larger tumour size than did mice in group 1 (Fig. $7 \mathrm{~b}-\mathrm{d}$ ). To evaluate the therapeutic efficacy of cisplatin in the control, co-culture and interference groups, we compared the differences in the tumour burden between groups 1 and 3 (control groups), groups 2 and 4 (co-culture groups) and groups 5 and 6 (interference groups). The results showed that in all the groups, cisplatin significantly reduced the tumour burden (Fig. 7b-e), whereas the percent reduction of tumour burden was significantly greater in the control group than in the co-culture group. Moreover, blocking IGF-1R could reverse CAF-mediated chemotherapy resistance (interference groups) (Fig. 7e). The results from the immunofluorescence double staining and immunohistochemistry (IHC) staining experiments also indicated that the expression of related key factors, including $\alpha$ SMA, IGF-1, ER $\beta$ and Bcl-2, was much higher in group 4 than in group 3. The expression of ER $\beta$ and $\mathrm{Bcl}-2$ was 


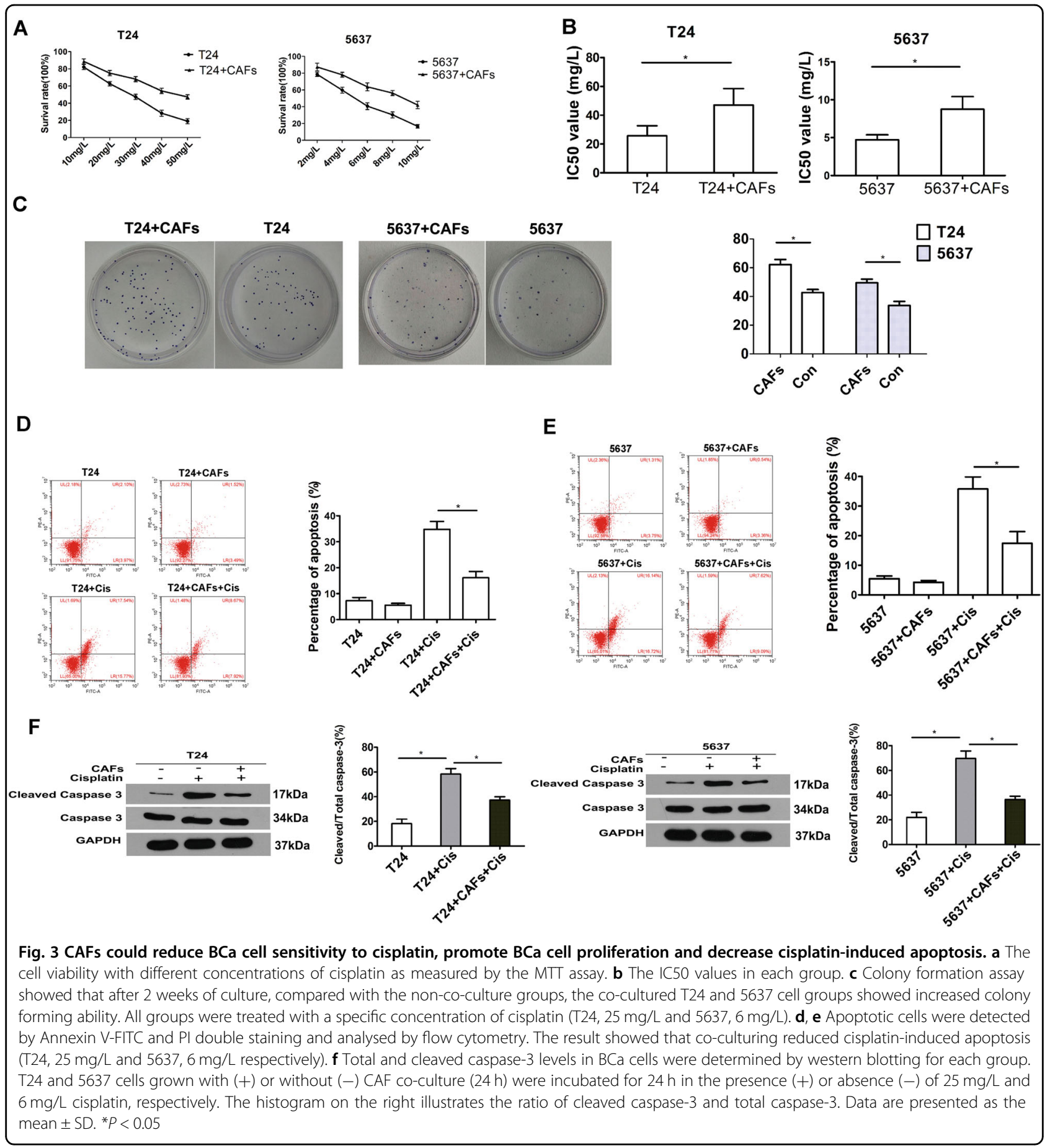

much lower in group 6 than in group 4 (Fig. 7f). An immunofluorescence double staining assay further confirmed that IGF-1 expression in the tumour stroma was closely correlated with the density of CAFs (Fig. 7g).

Our data indicate that $\mathrm{CAFs}$ in the $\mathrm{BCa}$ stroma enhanced cisplatin resistance of $\mathrm{BCa}$ by stimulating IGF$1 / \mathrm{ER} \beta / \mathrm{Bcl}-2$ signalling both in vitro and in vivo (Fig. 8).

\section{Discussion}

Chemoresistance is one major obstacle to improving the chemotherapy outcomes of $\mathrm{BCa}$ patients. CAFs, as a major component of the tumour microenvironment, participate in tumour initiation and progression upon activation by expressing proteins such as $\alpha$-SMA. Herein, our study for the first time explored the nature of $\mathrm{BCa}$ 

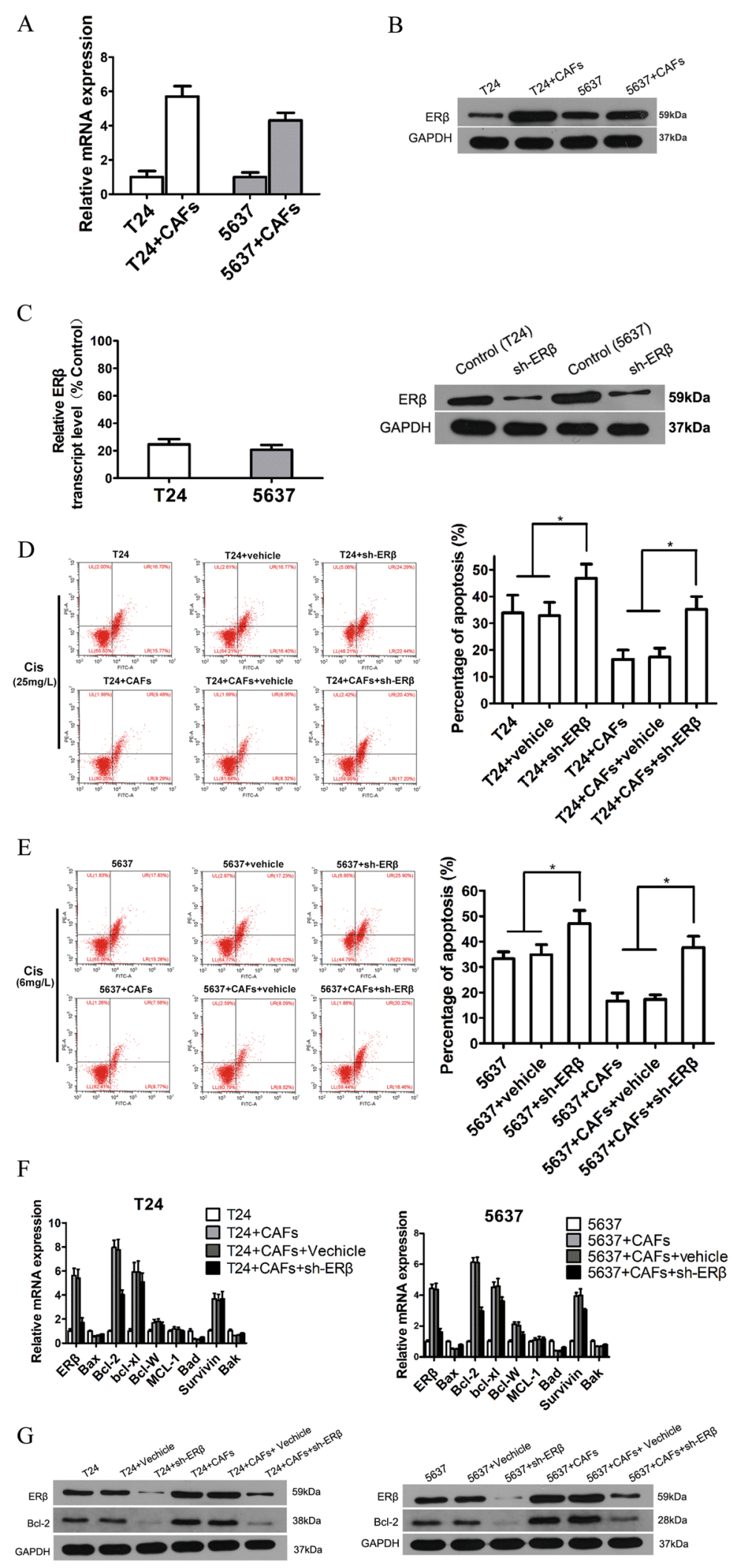

Fig. 4 (See legend on next page.) 
(see figure on previous page)

Fig. 4 CAFs could decrease BCa apoptosis induced by cisplatin via upregulation of ER $\beta / B C l-2$ signalling. a qRT-PCR results showed increased ERß expression in BCa cells (T24 and 5637) after co-culture with CAFs. The mean expression value of the control cells (T24, 5637) was defined as 1. b Western blotting results showed that ERB protein expression increased in BCa cells $(T 24,5637)$ after co-culture with CAFs. c Validation of the ERB shRNA knockdown efficiency in T24 and 5637 cells using western blotting (right) and relative mRNA expression (left) levels of ERß in T24 and 5637 cells at $48 \mathrm{~h}$ after transfection. Expression values were shown relative to those of the untreated group (control $=100 \%$ ) (left). $\mathbf{d}$, e Knocking down ER $\beta$ in BCa cells can reverse the effects of CAFs on BCa cell resistance to apoptosis induced by cisplatin (T24, $25 \mathrm{mg} / \mathrm{L} ; 5637,6 \mathrm{mg} / \mathrm{L})$. $\mathbf{f}$ qRT-PCR results showed that BCl-2 expression levels were significantly increased in both T24 and 5637 cells after co-culture with CAFs and could be partially reversed by ERß knockdown. The mean expression value of the control cells $(T 24,5637)$ was defined as 1. $\mathbf{g}$ Western blotting results showed that BCl-2 expression was increased in T24 and 5637 cells after co-culture with CAFs and decreased after knocking down ERß. All procedures were conducted after cells were cultured in an appropriate concentration of cisplatin $(T 24,25 \mathrm{mg} / \mathrm{L} ; 5637,6 \mathrm{mg} / \mathrm{L})$. Data are presented as the mean \pm SD. ${ }^{*} P<0.05$

resistance to chemotherapy from the perspective of the tumour microenvironment. We found that CAFs in the $\mathrm{BCa}$ stroma and the expression of ER $\beta$ in BCa were significantly associated with $\mathrm{OS}$ in patients treated with chemotherapy.

Previous epidemiological and preclinical studies demonstrated that ER $\beta$ signalling may play critical roles in the initiation and progression of $\mathrm{BCa}^{17-22}$, whereas few studies have discussed the relationship and potential mechanisms between the ER $\beta$ signalling pathway and $\mathrm{BCa}$ chemoresistance. We found that ER $\beta$ signalling also contributes to $\mathrm{BCa}$ chemoresistance, which may be mediated by CAFs. In vitro, we found that co-culture of $\mathrm{BCa}$ cells with CAFs significantly increased the expression of ER $\beta$ in BCa cells, and we showed that ER $\beta$ could be the signalling molecule upstream of Bcl-2 in BCa. Several other studies also demonstrated that $\mathrm{Bcl}-2$ expression was enhanced by ER $\beta$ in cardiomyocytes, medulloblastoma cells and $\mathrm{BCa}$ cells ${ }^{21,29,30}$. However, one study drew the opposite conclusion that ER $\beta$ may reduce $\mathrm{Bcl}-2$ expression in hormone-resistant breast cancer cells ${ }^{31}$.

Unlike ER $\alpha, E R \beta$ shows significant oestrogenindependent activities and can be phosphorylated and activated by various signals; in addition, changes in the phosphorylation state of ER $\beta$ might alter its ability to activate gene transcription ${ }^{32}$. This finding may explain why ER $\beta$ shows different functions in different types of cells and under different conditions. In the present study, we found that ER $\beta$ promoted Bcl-2 expression and reduced cancer cell apoptosis.

Previous studies showed that Bcl-2 expression can predict survival in patients receiving synchronous chemoradiotherapy for advanced $\mathrm{BCa}^{33}$, which is similar to our results. Upregulation of $\mathrm{Bcl}-2$ protein expression might be one of the mechanisms of cisplatin resistance in $\mathrm{BCa}$ cells ${ }^{34,35}$. Consistent with this possibility, an antisense $\mathrm{Bcl}-2$ oligonucleotide was reported to be helpful in reversing cisplatin resistance to chemotherapy in $\mathrm{BCa}^{34}$. Here, we proved that CAFs co-cultured with $\mathrm{BCa}$ cells could increase $\mathrm{Bcl}-2$ expression and contribute to increased $\mathrm{BCa}$ chemoresistance.

CAFs are the most abundant mesenchymal cell type present within the cancer-associated stroma for many cancers, including $\mathrm{BCa}^{35}$. CAFs can be derived from different precursor cell types, such as epithelial cells, inflammatory cells, endothelial cells, and bone marrow cells. However, the main source of CAFs is $\mathrm{NFs}^{9}$. These precursor cells are activated by a variety of chemokines and cytokines, including IGF-19. In our study, we found that IGF-1 was a vital cytokine in the recruitment and transformation of NFs to CAFs. However, the originating cell of IGF-1 in this context was unclear and required further study. Our preliminary results suggested that both $\mathrm{BCa}$ and CAFs contributed to the secretion of IGF-1, but CAFs might be the dominant cell of origin. Cytokines, chemokines and growth factors secreted by fibroblast-like tumour stromal cells can mediate drug resistance in several cancers via induction of gene transcription ${ }^{5}$. In addition, co-culture of $\mathrm{BCa}$ with CAFs can enhance the progression of $\mathrm{BCa}$ and induce epithelial-mesenchymal transition $^{36}$. In the present study, the in vitro and in vivo data demonstrated that CAFs could also promote cisplatin resistance of $\mathrm{BCa}$.

IGF-1 is a well-known autocrine and paracrine inducer of CAF activation ${ }^{9}$. Elevated expression of IGF-1 and IGF1R correlates with tumour progression, poor prognosis $^{37,38}$, apoptosis resistance and chemotherapy resistance ${ }^{39-41}$ in several cancer types, including BCa. Inhibiting IGF-1 and IGF-1R signalling has shown promising results in colorectal cancer by blocking the influence of its microenvironment ${ }^{42}$. In our study, blocking IGF-1 in the co-culture system reversed not only CAFmediated upregulation of $E R \beta$ and $\mathrm{Bcl}-2$ and the effects of CAF-mediated cisplatin resistance in $\mathrm{BCa}$ but also the capacity of BCa cells to transform NFs into CAFs.

In summary, our results showed that CAFs could promote cisplatin resistance in BCa cells by the IGF-1/ER $\beta$ / $\mathrm{Bcl}-2$ signalling pathway. Future studies may facilitate the development of an effective therapeutic strategy to disrupt these newly identified mechanisms in order to reverse resistance to cisplatin in $\mathrm{BCa}$.

\section{Materials and methods Patients}

During the median follow-up time of 37.5 (interquartile range, 25.5-47.25) months, 28 patients who had primary 


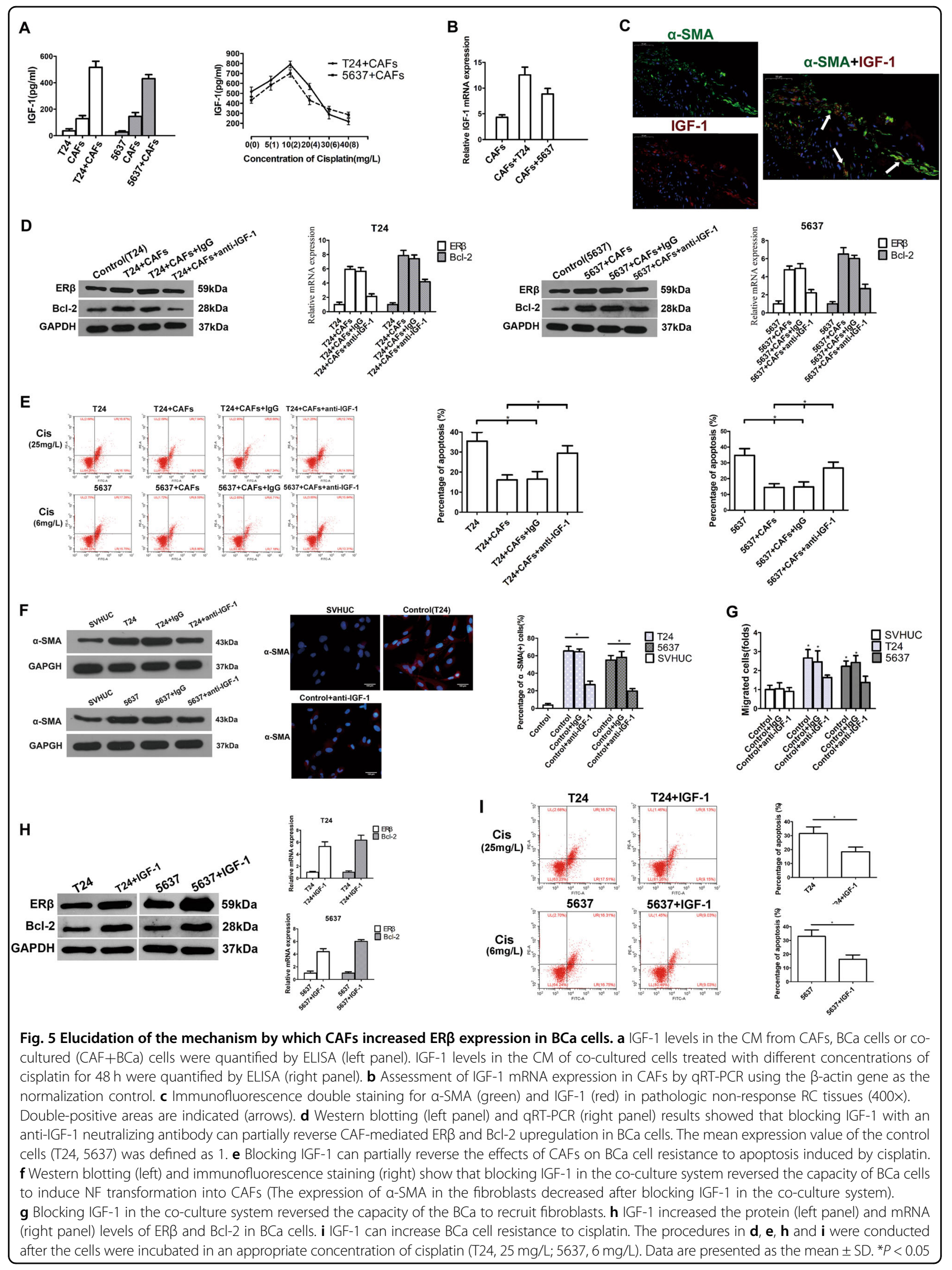



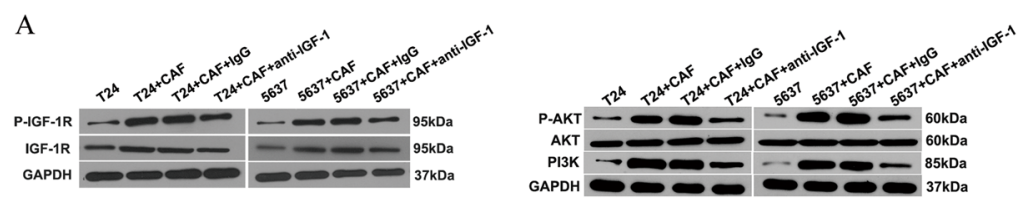

B

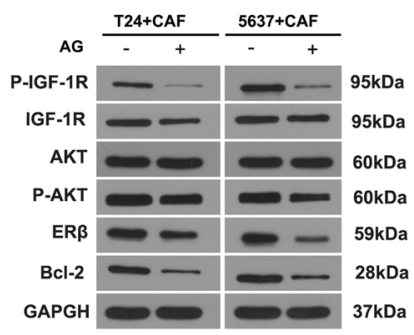

C

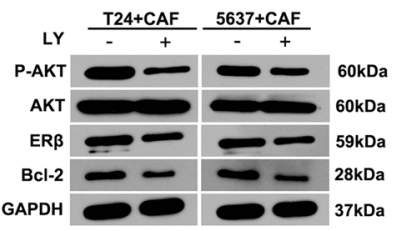

D

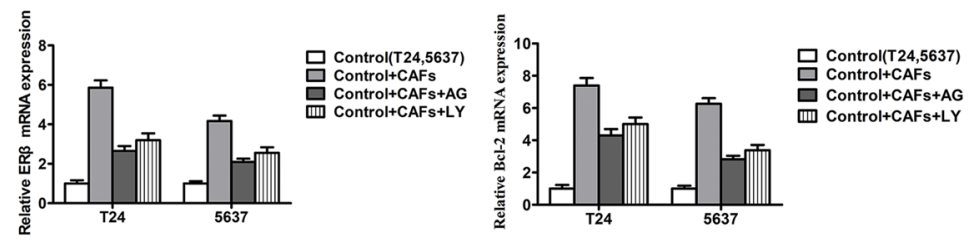

E
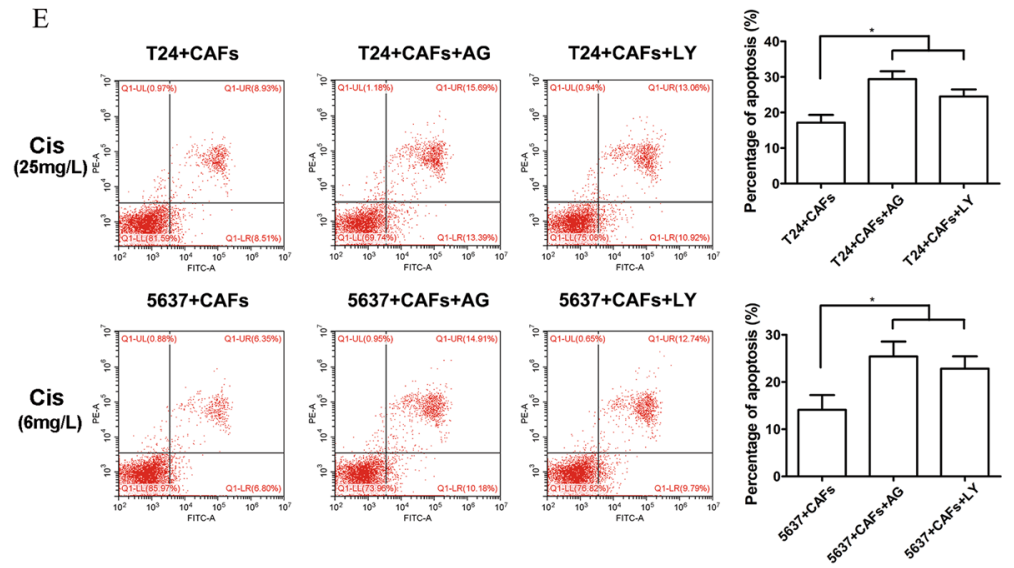

F
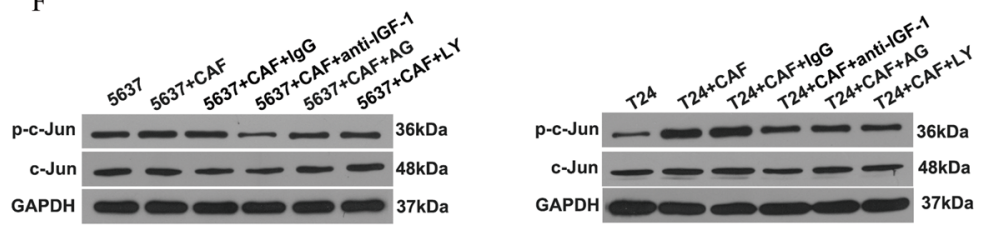

G
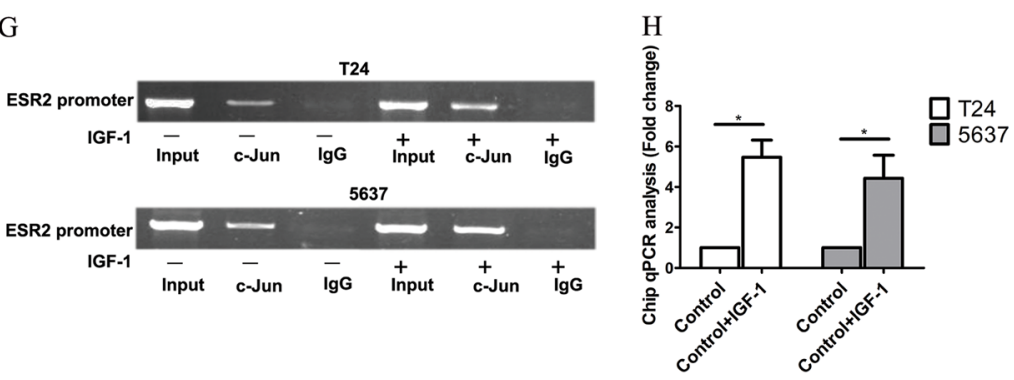

Fig. 6 (See legend on next page.) 
(see figure on previous page)

Fig. 6 CAFs increased ER $\beta$ expression via IGF-1/AKT/c-Jun signalling. a The expression of IGF-1R and PI3K and the phosphorylation of the IGF-1R and AKT proteins were increased after co-culture, but these effects were reversed by blocking IGF-1. b Western blotting showed that adding the IGF$1 R$ inhibitor $A G(1 \mu \mathrm{M})$ to the co-culture system could partially reverse CAF-mediated increases in the protein expression of ER $\beta$ and BCl-2 and the phosphorylation of IGF-1R and AKT. $\mathbf{c}$ Western blotting showed that ERB and Bcl-2 expression and AKT phosphorylation were decreased when the cells were pretreated with the AKT inhibitor $L Y(10 \mu M)$ in the co-culture system. $\mathbf{d}$ qRT-PCR results showed changes in ER $\beta$ and BCl-2 mRNA expression in BCa cells after co-culture upon pretreatment with $A G(1 \mu \mathrm{M})$ and $L Y(10 \mu \mathrm{M})$ for $1 \mathrm{~h}$ before co-culture. The mean expression value of the control cells $(T 24,5637)$ was defined as 1.0. e Both AG and LY can partially reverse the effects of CAFs on BCa cell resistance to cisplatin-induced apoptosis. $\mathbf{f}$ Phosphorylation of c-Jun was detected by western blotting in each group. $\mathbf{g}$ The cells were treated with or without IGF-1 for $8 \mathrm{~h}$. Then, the cells were harvested and subjected to chromatin ChIP with anti-c-Jun or control IgG, followed by qRT-PCR. $\mathbf{h}$ ChIP products were measured by real-time PCR. The expression value in the control group was defined as 1 . All procedures were conducted after cells were cultured in an appropriate concentration of cisplatin (T24, $25 \mathrm{mg} / \mathrm{L} ; 5637,6 \mathrm{mg} / \mathrm{L})$. Data are presented as the mean $\pm \mathrm{SD}$. ${ }^{*} P<0.05$

resectable MIBC (cT2-4aNOM0) and received at least three cycles of NAC before RC and pelvic lymph node dissection at our institution were retrospectively enrolled in this study. Pretreatment biopsy samples, resected RC samples of the tumour and adjacent normal bladder $(3 \mathrm{~cm}$ away from the tumour tissues) specimens were collected. Our study included patients with either pure urothelial carcinoma or urothelial carcinoma mixed with squamous and/or glandular differentiation. Patients with cT4b disease and all other variant histologies were excluded from analysis. The study was performed in accordance with the Declaration of Helsinki. Ethics approval was obtained from the ethics committee at Xiangya Hospital, and we obtained written informed consent from all participants in our study. Tumour staging was determined with the 2009 UICC-TNM staging system, and tumour grading was performed according to the World Health Organization (WHO) three-tiered classification ${ }^{43}$. The cisplatin/gemcitabine chemotherapy regimen was administered as follows: gemcitabine $1000 \mathrm{mg} / \mathrm{m}^{2}$, once on day 1 and on day 8 ; cisplatin $70 \mathrm{mg} / \mathrm{m}^{2}$, once on day 2 . This NAC regimen followed a 21-day cycle and was administered 16 weeks before RC surgery.

To obtain normal bladder specimens unaffected by NAC, adjacent normal bladder specimens from 10 patients with MIBC who underwent RC without NAC were also included in our study.

\section{Primary human CAF and NF isolation}

CAFs and NFs were isolated from human BCa specimens and adjacent normal tissues, respectively, using the method described by Zhuang et al. ${ }^{44}$. Tissues classified as MIBC of histological grade II were used for the isolation of stromal fibroblasts. The tissues were obtained from patients seen at Xiangya Hospital. Dulbecco's modified Eagle's medium/F12 medium supplemented with 10\% foetal bovine serum (FBS), 100 units $/ \mathrm{mL}$ penicillin and $100 \mu \mathrm{g} / \mathrm{mL}$ streptomycin was used to collect and culture the isolated cells. Then, a confluent and homogeneous monolayer of stromal fibroblasts was formed after 2-3 passages. The identification and characterization of primary human NFs and CAFs are shown in the Supplementary Materials and Methods and Supplementary Fig. S1.

To prepare $\mathrm{CM}$ from $\mathrm{BCa}$ cells co-cultured with CAFs, $\mathrm{BCa}$ cells were co-cultured with CAFs for $48 \mathrm{~h}$, and the collected medium was centrifuged for $10 \mathrm{~min}$ at $3000 \mathrm{rpm}$ to remove cell debris. The fibroblasts used in the experiments were at $<10$ passages.

\section{Cell culture}

The normal human urothelial cell line SVHUC and the human BCa cell lines T24 and 5637 were obtained from Auragene Bioscience Corporation Inc. Kaighn's modification of Ham's F12 medium supplemented with 10\% FBS was used to culture the SVHUCs. BCa cells were maintained in RPMI-1640 supplemented with $10 \%$ FBS, 100 units $/ \mathrm{mL}$ penicillin and $100 \mu \mathrm{g} / \mathrm{mL}$ streptomycin. All cells were cultured at $37{ }^{\circ} \mathrm{C}$ in a humidified environment containing $5 \% \mathrm{CO}_{2}$.

\section{Transwell noncontact co-culture system}

We employed a transwell noncontact co-culture system (24 well), with inserts with a $0.4 \mu \mathrm{m}$ pore size polycarbonate membrane (Corning, \#3413, Corning, NY, USA) for all co-culture assays except the fibroblast recruitment assay. A total of $1 \times 10^{5}$ of either CAFs or NFs and $\mathrm{BCa}$ cells were plated into the upper and lower chambers of the transwells, respectively. Cells in the upper or lower chambers are unable to migrate through the $0.4 \mu \mathrm{m}$ pores of the polycarbonate membrane, which creates a noncontact co-culture system.

\section{Fibroblast recruitment assay}

This assay was implemented in a transwell system (24 well) with a polycarbonate membrane containing $5-\mu \mathrm{m}$ pores (Corning, \#3421, Corning, NY, USA). A total of $1 \times$ $10^{5}$ NFs was plated into the upper chambers of the transwells, and SVHUCs or BCa cells were plated into the lower chambers. We collected and counted the number of 

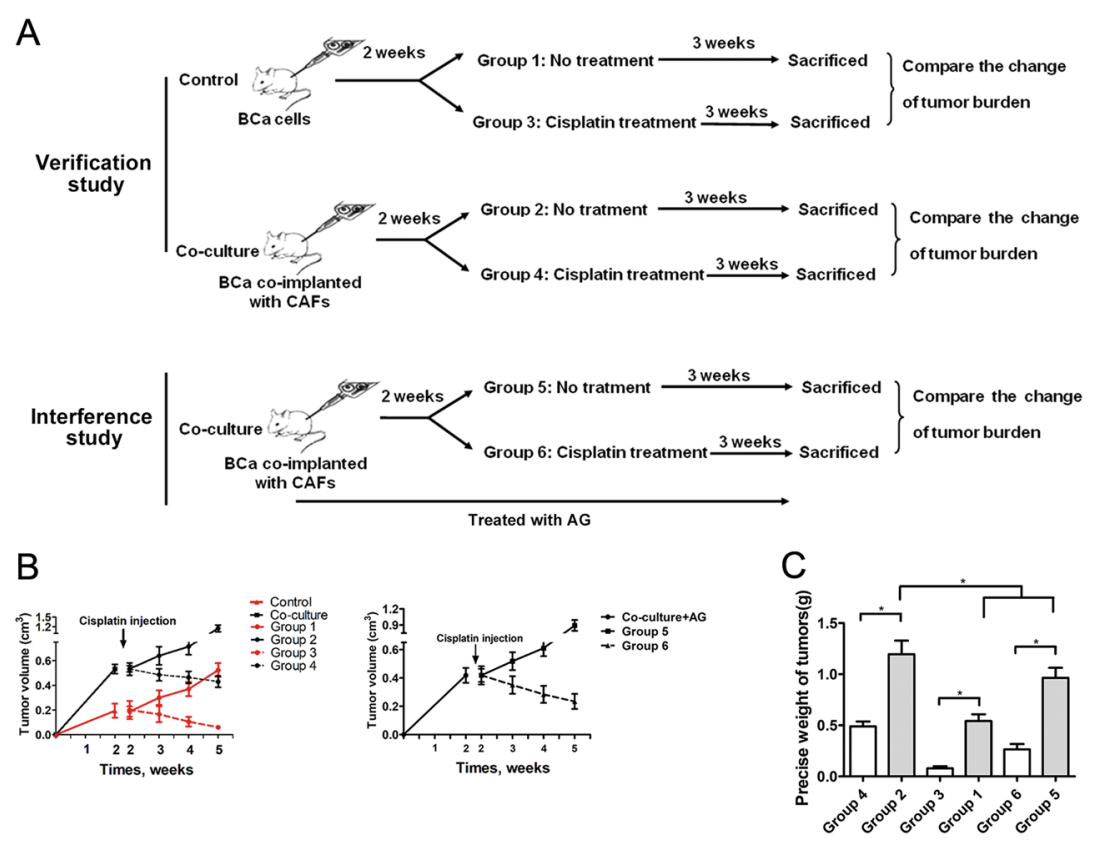

D

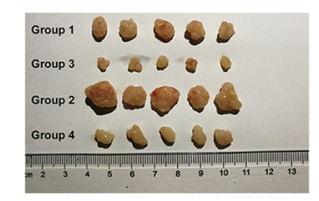

F

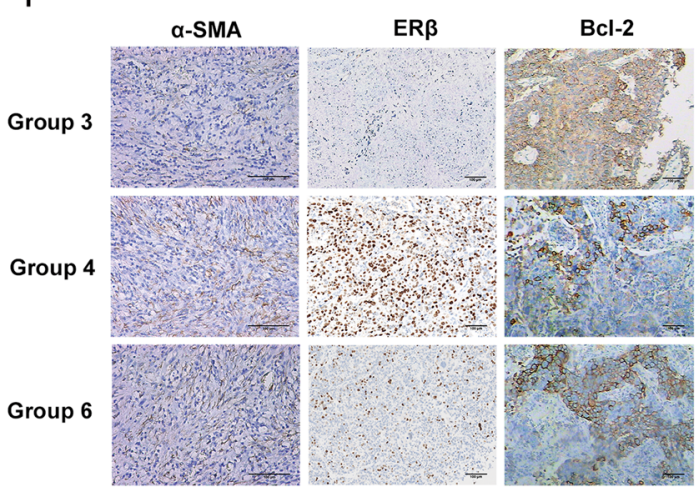

G

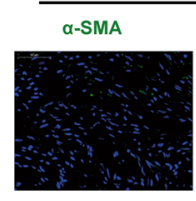

IGF-1
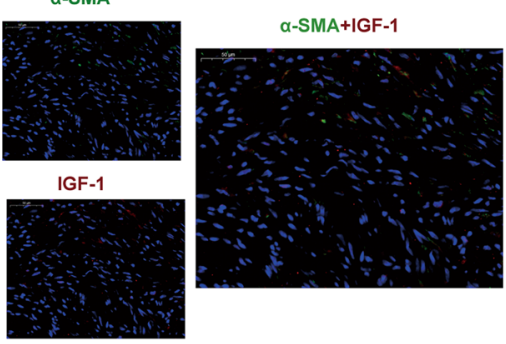

Group 3

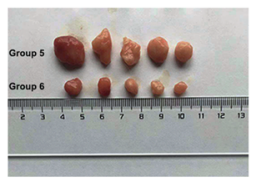

E
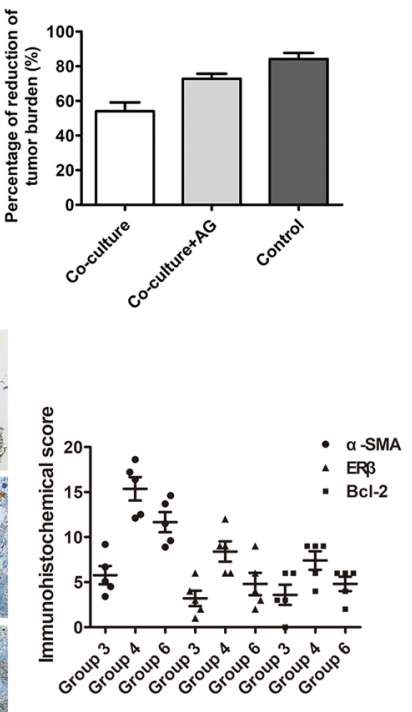

Group 4

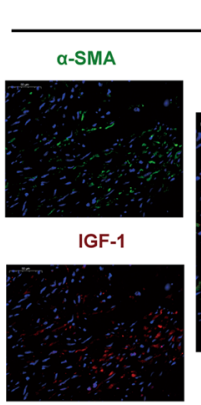

$\alpha-S M A+\mid G F-1$

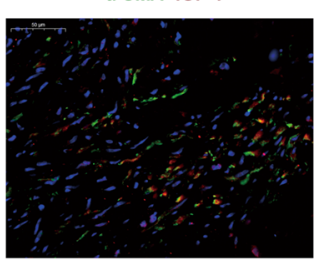

Fig. 7 (See legend on next page.) 
(see figure on previous page)

Fig. 7 CAFs reduced BCa sensitivity to cisplatin by stimulating IGF-1/ER $\beta / B C l-2$ signalling in vivo. a Grouping and intervention schemes. b Changes in the tumour volumes of each group in the verification and intervention study. Tumour volumes were calculated as described in the Materials and methods section. Arrows represent the start of cisplatin treatment, $n=5$ per group. The mice were sacrificed after completion of the treatments. c, d Quantification of the tumour sizes in each group in the verification and intervention studies after mice were sacrificed. e The percent reduction of tumour burden was calculated to evaluate the effect of cisplatin treatment as follows: percent reduction of tumour burden $=$ (no treatment group - treatment group)/ no treatment group $\times 100 \%$. $\mathbf{f} \| \mathrm{HC}$ staining for a-SMA, ERB and BCl-2 in xenograft bladder tumour tissues (aSMA, 200x; ERß and BCl-2, 100x) in each group. $\mathbf{g}$ Double fluorescence staining of a-SMA (green) and IGF-1 (red) in xenograft bladder tumour tissues (400X). Data are presented as the mean \pm SD. ${ }^{*} P<0.05$

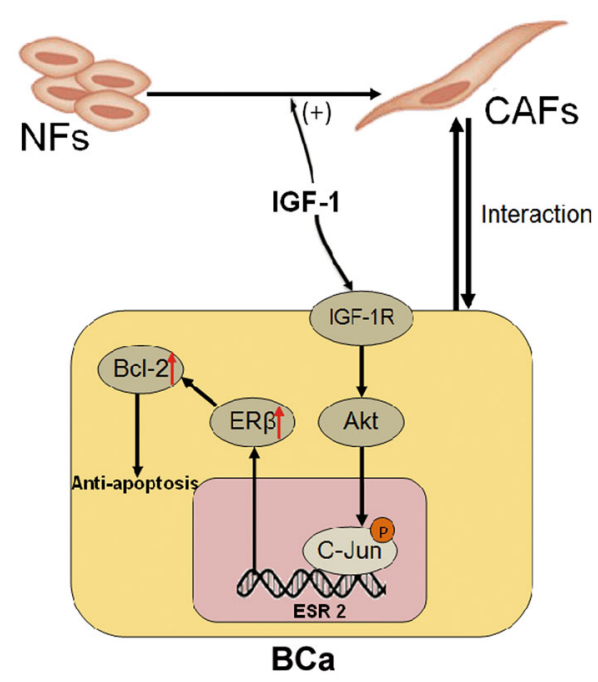

Fig. 8 Cartoon illustration summarizing CAF-enhanced cisplatin resistance via stimulating IGF-1/ER $\beta / \mathrm{BCl}-2$ signalling in the tumour microenvironment of $\mathbf{B C a}$. The red arrows indicated an increase in $\mathrm{ER} \beta$ and $\mathrm{BCl}-2$ expression

fibroblasts that migrated into the lower chamber after $8 \mathrm{~h}$ of co-culture.

\section{MTT assay}

$\mathrm{BCa}$ cells (with or without co-culture for $24 \mathrm{~h}$ ) or fibroblasts (CAFs or NFs) in the exponential growth phase were plated in 96-well plates at a density of $3 \times 10^{3}$ cells/ well. Next, fresh medium or co-culture medium containing different concentrations of cisplatin was used to replace the original culture medium. Then, after $72 \mathrm{~h}$ of culture, 3-(4,5-dimethyl-2-thiazolyl)-2,5-diphenyl-2-Htetrazolium bromide, thiazolyl blue tetrazolium bromide (MTT) $(20 \mu \mathrm{L} /$ well $)$ was added to each well and incubated with the cells for $2 \mathrm{~h}$, after which an ELISA reader (ELX800 , Bio-Tek) was used to measure the optical density of each well at $570 \mathrm{~nm}$ (OD570). GraphPad 5 software (GraphPad Software, CA, USA) was used to calculate the inhibition rate of every concentration and the IC50 (half maximal inhibitory concentration) value of cisplatin on all the tested cells.

\section{Cell apoptosis assay}

After $48 \mathrm{~h}$ with or without co-culture, cells from all groups were seeded at a density of $5 \times 10^{5}$ cells per $10 \mathrm{~mm}$ dish with fresh or co-culture medium and treated with the indicated concentrations of cisplatin for $24 \mathrm{~h}$. After brief trypsinization, the cells were collected and washed twice in phosphate-buffered saline. After the cells were incubated with $10 \mu \mathrm{L}$ of propidium iodide (PI) and $5 \mu \mathrm{L}$ of annexin V-Fluorescein isothiocyanate (V-FITC) at room temperature in the dark for $15 \mathrm{~min}$, they were analysed by flow cytometry (BD, NJ, USA). Cells with a low PI signal and a high annexin $\mathrm{V}$ fluorescence signal were regarded as apoptotic cells. The percentages of apoptotic cells were calculated by data obtained from the fluorescence activated cell sorting (FACS) analysis.

\section{Colony formation assay}

For all the groups, 150 cells in $3 \mathrm{~mL}$ of medium (either complete medium with the indicated concentration of cisplatin or co-culture $\mathrm{CM}$ with the indicated concentration of cisplatin) were seeded in each well of a sixwell plate. The plates were incubated at $5 \% \mathrm{CO}_{2}, 37^{\circ} \mathrm{C}$ for 2 weeks. Then, the cells were gently washed and stained with Giemsa. After the cells were cultured for another 2 weeks, the cloning efficiency was calculated; colonies possessing at least 50 cells were counted.

\section{Lentivirus packaging and cell transfection}

As previously reported, sh-ER $\beta$ was constructed in the pLKO.1 lentiviral vector ${ }^{45}$. To prepare the ER $\beta$ shRNA lentivirus particles, pLKO.1 sh-ER $\beta$ together with packaging and envelope plasmids (psPAX2 and pMD2G, respectively) was transfected into $293 \mathrm{~T}$ cells. The resulting lentivirus supernatant was collected and stored at $-80^{\circ} \mathrm{C}$ for later use in the transduction of $\mathrm{BCa}$ cells.

\section{ChIP}

First, $1 \%$ formaldehyde was added to cross-link the cells, and $10 \mathrm{~min}$ later, glycine was used to stop the reaction. To shear genomic DNA from the cross-linked cells, micrococcal nuclease was used to lyse and enzymatically digest the cells. An anti-c-Jun antibody (Abcam) was used for immunoprecipitation, with IgG serving as a negative 
control. After the protein/DNA complexes were eluted from the beads, they were treated with proteinase $\mathrm{K}$ solution for $2.5 \mathrm{~h}$ at $65^{\circ} \mathrm{C}$ and then analysed by real-time PCR and semiquantitative PCR using primers for the ESR2 promoter. The specific primers used to amplify target sequences from human ER $\beta$ promoters are listed in Supplementary Table S3.

\section{Xenograft mouse model}

Six- to 8-week-old female nude mice (BALB/C-nu) were purchased from the animal centre of Xiangya Medical School. All experimental procedures were approved by the Institutional Animal Care and Use Committee of Xiangya Hospital. The total duration of the in vivo experiment was 5 weeks. For the verification study, in the first 2 weeks, the mice were randomly assigned into two groups. In the control group, 10 mice were implanted with $1 \times 10^{6} \mathrm{BCa}$ T24 cells only, whereas in the co-culture group, 10 mice were co-implanted with $1 \times 10^{6} \mathrm{BCa}$ T24 cells and $1 \times 10^{5}$ CAFs. Three weeks later, the mice were assigned to one of four groups: group 1, control group, no other treatment; group 2, co-culture group, no other treatment; group 3, control group, intravenous injection with cisplatin at $1 \mathrm{mg} / \mathrm{kg}$ body weight (Selleck Chemicals, Houston, USA) twice every week; and group 4, co-culture group, intravenous injection of cisplatin as described for group 3. The above-mentioned doses of cisplatin were reported to be effective and safe by previous studies ${ }^{46}$. In the interference study, 10 mice were administered AG $(0.2 \mathrm{nM} / \mathrm{g})$ (Millipore) via oral gavage every 3 days throughout the study. During the first 2 weeks, all mice were co-implanted with $1 \times 10^{6} \mathrm{BCa}$ T24 cells and $1 \times 10^{5}$ CAFs. Three weeks later, the mice were randomly assigned into two groups: group 5, no other treatment; and group 6, intravenous injection of cisplatin as described for groups 3 and 4 .

The grouping and intervention schemes are shown in Fig. 7a. Tumours were measured using a calliper once a week after xenografting until the mice were sacrificed, and the tumour volume was estimated as $a b^{2} \pi / 6$, where $a$ represents the largest diameter and $b$ represents the largest diameter perpendicular to $a$. When the mice were sacrificed, the precise weights of the tumours were measured, and the tumours were processed for IHC and fluorescence staining.

\section{Statistical analysis}

All data are presented as the mean \pm SD or median \pm quartile from at least three independent experiments. Variables for the different groups were compared using analysis of variance, the Mann-Whitney $U$-test and the chi-square test as appropriate. To determine the best cut-offs of continuous variables for predicting patient survival and pathologic response, the receiver operating characteristic (ROC) curve method was performed as described in a previous study ${ }^{47}$. A logistic regression model was used in the univariate and multivariate analyses. For internal validation, the models were subjected to 1000 bootstrap resamples. Survival curves were plotted by the Kaplan-Meier method, and differences were examined by the log-rank test. Statistical analyses were performed with SPSS 17.0 (SPSS Inc., Chicago, IL). $P<0.05$ was considered statistically significant.

Reagents, materials and details relating to tissue IHC, immunofluorescence, RNA extraction, real-time PCR quantitation, western blotting analysis and ELISA are described in the Supplementary Materials and Methods. All primers used in real-time PCR are listed in Supplementary Table S3.

\section{Acknowledgements \\ This work is supported by the following grants: the National Natural Science Foundation of China (no. 81001137 and no. 81874094), the Innovation and Entrepreneurship in South Central University project (no. 2017gczd032) and the project from Health and Family Planning Commission of Hunan Province (no. C20180105). \\ Author details \\ 'Department of Urology, Xiangya Hospital, Central South University, Changsha 410008 Hunan, China. ${ }^{2}$ Department of Urology, Beijing Hospital, National Centre of Gerontology, Graduate School of Peking Union Medical College, 100730 Beijing, China. ${ }^{3}$ Department of Ophthalmology, Xiangya Hospital, Central South University, Changsha 410008 Hunan, China}

\section{Conflict of interest}

The authors declare that they have no conflict of interest.

\section{Publisher's note}

Springer Nature remains neutral with regard to jurisdictional claims in published maps and institutional affiliations.

Supplementary Information accompanies this paper at (https://doi.org/ 10.1038/s41419-019-1581-6).

Received: 1 July 2018 Revised: 28 March 2019 Accepted: 2 April 2019 Published online: 10 May 2019

\footnotetext{
References

1. Torre, L. A. et al. Global cancer statistics, 2012. CA Cancer J. Clin. 65, 87-108 (2015).

2. Gallagher, D. J., Milowsky, M. I. \& Bajorin, D. F. Advanced bladder cancer: status of first-line chemotherapy and the search for active agents in the second-line setting. Cancer 113, 1284-1293 (2008).

3. von der Maase, H. et al. Gemcitabine and cisplatin versus methorexate, vinblastine, doxorubicin and cisplatin in advanced or metastatic bladder cancer: results of a large, randomized, multinatinal, multicenter, phase III study. J. Clin. Oncol. 18, 3068-3077 (2000).

4. Grossman, H. B. et al. Neoadjuvant chemotherapy plus cystectomy compared with cystectomy alone for locally advanced bladder cancer. N. Engl. J. Med. 349, 859-866 (2003).

5. Meads, M. B., Gatenby, R. A. \& Dalton, W. S. Environment-mediated drug resistance: a major contributor to minimal residual disease. Nat. Rev. Cancer $\mathbf{9}$, 665-674 (2009).

6. Trédan, O., Galmarini, C. M., Patel, K. \& Tannock, I. F. Drug resistance and the solid tumor microenvironment. J. Natl. Cancer Inst. 99, 1441-1454 (2007).
} 
7. Shen, Z. H. et al. Targeting of the leukemia microenvironment by c(RGDfV) overcomes the resistance to chemotherapy in acute myeloid leukemia in biomimetic polystyrene scaffolds. Oncol. Lett. 12, 3278-3284 (2016).

8. Martinez-Outschoorn, U. E., Lisanti, M. P. \& Sotgia, F. Catabolic cancerassociated fibroblasts transfer energy and biomass to anabolic cancer cells, fueling tumor growth. Semin. Cancer Biol. 25, 47-60 (2014).

9. Kalluri, R. \& Zeisberg, M. Fibroblasts in cancer. Nat. Rev. Cancer 6, 392-401 (2006).

10. Yan, H., Guo, B. Y. \& Zhang, S. Cancer-associated fibroblasts attenuate cisplatininduced apoptosis in ovarian cancer cells by promoting STAT3 signaling. Biochem. Biophys. Res. Commun. 470, 947-954 (2016).

11. Müerköster, S. S. et al. Role of myofibroblasts in innate chemoresistance of pancreatic carcinoma-epigenetic downregulation of caspases. Int. J. Cancer 123, 1751-1760 (2008).

12. Li, J., Guan, J., Long, X., Wang, Y. \& Xiang, X. Mir-1-mediated paracrine effect of cancer-associated fibroblasts on lung cancer cell proliferation and chemoresistance. Oncol. Rep. 35, 3523-3531 (2016).

13. Cook, M. B. et al. Sex disparities in cancer incidence by period and age. Cancer Epidemiol. Biomarkers Prev. 18, 1174-1182 (2009).

14. Scosyrev, E., Noyes, K., Feng, C. \& Messing, E. Sex and racial differences in bladder cancer presentation and mortality in the US. Cancer 115, 68-74 (2009).

15. Bjornstrom, L. \& Sjoberg, M. Mechanisms of estrogen receptor signaling: convergence of genomic and nongenomic actions on target genes. Mol. Endocrinol. 19, 833-842 (2005).

16. Shen, S. S. et al. Expression of estrogen receptors- $a$ and $-\beta$ in bladder cancer cell lines and human bladder tumor tissue. Cancer 106, 2610-2616 (2006).

17. Miyamoto, $H$. et al. Expression of androgen and oestrogen receptors and its prognostic significance in urothelial neoplasm of the urinary bladder. BJU Int 109, 1716-1726 (2012)

18. Han, B., Cui, D., Jing, Y., Hong, Y. \& Xia, S. Estrogen receptor beta (ERß) is a novel prognostic marker of recurrence survival in non-muscle-invasive bladder cancer potentially by inhibiting cadherin switch. World J. Urol. 32, 149-155 (2014).

19. Kauffman, E. C. et al. Estrogen receptor-beta expression and pharmacological targeting in bladder cancer. Oncol. Rep. 30, 131-138 (2013).

20. Tuygun, C. et al. Sex-specific hormone receptors in urothelial carcinomas of the human urinary bladder: a comparative analysis of clinicopathological features and survival outcomes according to receptor expression. Urol. Oncol. 29, 43-51 (2011).

21. Huang, W. et al. Roles of ERß and GPR30 in proliferative response of human bladder cancer cell to estrogen. Biomed. Res. Int. 2015, 251780 (2015).

22. Hsu, I. et al. Suppression of ERß signaling via ER $\beta$ knockout or antagonist protects against bladder cancer development. Carcinogenesis 35, 651-661 (2014).

23. Kwak, Y. et al. The clinical implication of cancer-associated microvasculature and fibroblast in advanced colorectal cancer patients with synchronous or metachronous metastases. PLoS ONE 9, e91811 (2014).

24. Tsujino, T. et al. Stromal myofibroblasts predict disease recurrence for colorectal cancer. Clin. Cancer Res. 13, 2082-2090 (2007).

25. Dranoff, G. Cytokines in cancer pathogenesis and cancer therapy. Nat. Rev. Cancer 4, 11-22 (2004).

26. Rizza, P. et al. Estrogen receptor beta as a novel target of androgen receptor action in breast cancer cell lines. Breast Cancer Res. 16, R21 (2014).

27. Li, L. C., Yeh, C. C., Nojima, D. \& Dahiya, R. Cloning and characterization of human estrogen receptor beta promoter. Biochem. Biophys. Res. Commun. 275, 682-689 (2000)
28. Manna, P. R. et al. Molecular mechanisms of insulin-like growth factor-I mediated regulation of the steroidogenic acute regulatory protein in mouse leydig cells. Mol. Endocrinol. 20, 362-378 (2006).

29. Hsieh, D. J. et al. 17ß-Estradiol and/or estrogen receptor $\beta$ attenuate the autophagic and apoptotic effects induced by prolonged hypoxia through HIF-1a-mediated BNIP3 and IGFBP-3 signaling blockage. Cell. Physiol. Biochem. 36, 274-284 (2015)

30. Cookman, C. J. \& Belcher, S. M. Estrogen receptor- $\beta$ up-regulates IGF1R expression and activity to inhibit apoptosis and increase growth of medulloblastoma. Endocrinology 156, 2395-2408 (2015).

31. Ruddy, S. C. et al. Preferential estrogen receptor $\beta$ ligands reduce $\mathrm{BCl}-2$ expression in hormone-resistant breast cancer cells to increase autophagy. Mol. Cancer Ther. 13, 1882-1893 (2014).

32. Thomas, C. \& Gustafsson, J. A. The different roles of ER subtypes in cancer biology and therapy. Nat. Rev. Cancer 11, 597-608 (2011).

33. Hussain, S. A. et al. BCL2 expression predicts survival in patients receiving synchronous chemoradiotherapy in advanced transitional cell carcinoma of the bladder. Oncol. Rep. 10, 571-576 (2003).

34. Hong, J. H., Lee, E., Hong, J., Shin, Y. J. \& Ahn, H. Antisense Bcl2 oligonucleotide in cisplatin-resistant bladder cancer cell lines. BJU Int. 90, 113-117 (2002).

35. Mitchell, M. I. \& Engelbrecht, A. M. Metabolic hijacking: a survival strategy cancer cells exploit? Crit. Rev. Oncol. Hematol. 109, 1-8 (2017).

36. Shi, $\mathrm{H}$. et al. Overexpression of monocarboxylate anion transporter 1 and 4 in T24-induced cancer-associated fibroblasts regulates the progression of bladder cancer cells in a 3D microfluidic device. Cell. Cycle 14, 3058-3065 (2015).

37. Surmacz, E. Growth factor receptors as therapeutic targets: strategies to inhibit the insulin-like growth factor I receptor. Oncogene 22, 6589-6597 (2003).

38. Pollack, M. The insulin and insulin-like growth factor receptor family in neoplasia: an update. Nat. Rev. Cancer 12, 159-169 (2012).

39. Koti, M. et al. Identification of the IGF1/PI3K/NF kappaB/ERK gene signalling networks associated with chemotherapy resistance and treatment response in high-grade serous epithelial ovarian cancer. BMC Cancer 13, 549 (2013).

40. Tracz, A. F., Szczylik, C., Porta, C. \& Czarnecka, A. M. Insulin-like growth factor-1 signaling in renal cell carcinoma. BMC Cancer 16, 453 (2016).

41. Sun, H. Z., Wu, S. F. \& Tu, Z. H. Blockage of IGF-1R signaling sensitizes urinary bladder cancer cells to mitomycin-mediated cytotoxicity. Cell. Res. 11, 107-115 (2001).

42. Sanchez-Lopez, E. et al. Targeting colorectal cancer via its microenvironment by inhibiting IGF-1 receptor-insulin receptor substrate and STAT3 signaling. Oncogene 35, 2634-2644 (2016).

43. Sauter G., et al. Noninvasive urothelial neoplasia: WHO classification of noninvasive papillary urothelial tumors. (eds Eble J. N., Sauter G., Epstein J. I. \& Sesterhenn I.) in World Health Organization Classification of Tumors. Pathology and Genetics of Tumors of the Urinary System and Male Genital Organs. pp.89-157 (IARC Press, Lyon, 2004).

44. Zhuang, J. et al. TGFB1 secreted by cancer-associated fibroblasts induces epithelial-mesenchymal transition of bladder cancer cells through IncRNAZEB2NAT. Sci. Rep. 5, 11924 (2015).

45. Hsu, I. et al. Estrogen receptor alpha prevents bladder cancer via INPP4B inhibited akt pathway in vitro and in vivo. Oncotarget 5, 7917-7935 (2014).

46. Miyake, H., Hara, I., Hara, S., Arakawa, S. \& Kamidono, S. Synergistic chemosensitization and inhibition of tumor growth and metastasis by adenovirusmediated P53 gene transfer in human bladder cancer model. Urology 56, 332-336 (2000).

47. Budczies, J. et al. Cutoff Finder: a comprehensive and straightforward Web application enabling rapid biomarker cutoff optimization. PLOS ONE 7, e51862 (2012). 